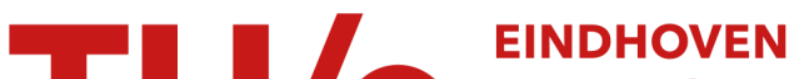 \\ UNIVERSITY OF \\ TECHNOLOGY
}

\section{Translating nanomedicines: Thinking beyond materials?}

\section{Citation for published version (APA):}

Witzigmann, D., Hak, S., \& van der Meel, R. (2018). Translating nanomedicines: Thinking beyond materials? a young investigator's reply to 'The Novelty Bubble'. Journal of Controlled Release, 290, 138-140.

https://doi.org/10.1016/j.jconrel.2018.10.011

DOI:

10.1016/j.jconrel.2018.10.011

Document status and date:

Published: 28/11/2018

\section{Document Version:}

Accepted manuscript including changes made at the peer-review stage

\section{Please check the document version of this publication:}

- A submitted manuscript is the version of the article upon submission and before peer-review. There can be important differences between the submitted version and the official published version of record. People interested in the research are advised to contact the author for the final version of the publication, or visit the $\mathrm{DOI}$ to the publisher's website.

- The final author version and the galley proof are versions of the publication after peer review.

- The final published version features the final layout of the paper including the volume, issue and page numbers.

Link to publication

\section{General rights}

Copyright and moral rights for the publications made accessible in the public portal are retained by the authors and/or other copyright owners and it is a condition of accessing publications that users recognise and abide by the legal requirements associated with these rights.

- Users may download and print one copy of any publication from the public portal for the purpose of private study or research.

- You may not further distribute the material or use it for any profit-making activity or commercial gain

- You may freely distribute the URL identifying the publication in the public portal.

If the publication is distributed under the terms of Article 25fa of the Dutch Copyright Act, indicated by the "Taverne" license above, please follow below link for the End User Agreement:

www.tue.nl/taverne

Take down policy

If you believe that this document breaches copyright please contact us at:

openaccess@tue.nl

providing details and we will investigate your claim. 


\title{
Translating nanomedicines: Thinking beyond materials? A young investigator's reply to 'The Novelty Bubble'
}

\author{
Dominik Witzigmann ${ }^{\mathrm{a}, * *}$, Sjoerd Hak ${ }^{\mathrm{b}, *}$, Roy van der Meel ${ }^{\mathrm{a}, \mathrm{c}, * *}$ \\ ${ }^{a}$ Department of Biochemistry and Molecular Biology, University of British Columbia, Vancouver, British Columbia, Canada \\ ${ }^{\mathrm{b}}$ Department of Circulation and Medical Imaging, The Norwegian University of Science and Technology, Trondheim, Norway \\ ${ }^{\mathrm{c}}$ Department of Clinical Chemistry and Haematology, University Medical Center Utrecht, Utrecht, Netherlands
}

\section{Novelty first, applicability second?}

The Journal of Controlled Release (JCR) regularly publishes editorials and opinion pieces to trigger discussions on the current status of the nanomedicine and drug delivery fields. These contributions are generally written by established, leading scientists. Most recently, Prof. Jean-Christophe Leroux (ETH Zürich) wrote an apt Perspective entitled 'The Novelty Bubble'. In that article he describes how the 'novelty' criterion of high-impact journals is driving the publication of nanomedicine studies that detail increasingly complex nanomaterials with limited clinical applicability [1].

As early-stage career scientists, we are actively striving to publish in top-tier journals to increase our chances for research funding and to advance our careers. In addition to our individual goals, publishing entails the opportunity and responsibility to shape the future of nanomedicine research.

Leroux rightfully indicates that an ongoing trend in our field is to predominantly associate novelty with developing innovative nanomaterials, while little emphasis is put on understanding these materials' interactions within the body or their potential for clinical translation. Apart from a small number of successful approved nanotherapeutics, the field's predominant foci are developing new formulations and executing numerous preclinical proof-of-principle studies, with an emphasis on future potential.

Although developing and characterizing new materials is undoubtedly vital for improving drug delivery and has been instrumental in establishing the nanomedicine field, these studies do not propel translation. It is becoming increasingly evident that even the most fundamental interactions of (approved) nanomedicines within the body are far more complex than previously anticipated. Limited insight into these nano-bio interactions - combined with overgeneralized, long-standing dogmas such as the enhanced permeability and retention (EPR) effect is a major contributor to nanomedicines' poor clinical translation [2,3]. We have an obligation to look beyond proof-of-principles and improve the development of nanomedicines. Our field's purpose is to positively improve patients' lives, not merely to achieve proof of therapeutic potential in mice. Therefore, we advocate a shift wherein novelty does not only include engineering new nanomaterials, but also comprises studying their in vivo behavior in great detail. In other words, we have to progress beyond the black box paradigm and put more focus on the in vivo properties that foster clinical translation.

\section{Re-thinking novelty: shifting the focus from materials to medicine}

As pointed out by Leroux, novelty is often linked to complexity. A trend in the last decade has been to encapsulate multiple drugs in (responsive) multifunctional nanoparticles that are additionally equipped with targeting ligands and imaging agents. There is a notable disparity between the complex drug delivery systems described in high-impact papers and the relative simplicity of clinically approved nanomedicines. For example, Vyxeos ${ }^{\mathrm{TM}}$, recently approved to treat acute myeloid leukemia, is the first cancer nanomedicine that demonstrated improved overall survival, as compared to standard of care, in a phase III study. The formulation and its production are relatively simple (from a formulation scientist point of view): liposomes with remotely loaded cytarabine and daunorubicin [4]. More complex formulations, such as ligand-equipped or theranostic nanomedicines, certainly have scientific value, but their introduction in clinical settings has been limited [5]. This is not only related to the formulations' complexity; their clinical

\footnotetext{
* all authors contributed equally

* Corresponding authors at: Department of Biochemistry and Molecular Biology, University of British Columbia, Vancouver, British Columbia, Canada.

Email addresses: dominik.witzigmann@ubc.ca (D. Witzigmann); sjoerd.hak@ntnu.no (S. Hak); R.vanderMeel@umcutrecht.nl (R. van der Meel)
} 
translation is also hindered by other obstacles, such as unfavorable cost-effectiveness, challenges in scale-up and GMP manufacturing, and regulatory requirements [6]. This at least partly explains the advocacy for simplicity in developing clinically relevant nanomedicines [7].

In the field of nanomedicine, novelty can certainly lie in developing new nanomaterials, but novelty can also come from fundamental discoveries that increase our understanding of (existing) drug delivery systems, their in vivo behavior, and strategies that facilitate clinical translation. For example, Onpattro ${ }^{\mathrm{TM}}$ (patisiran), a lipid nanoparticle formulation containing siRNA, is the first approved RNAi therapeutic following a decade of systematic research [8]. Interestingly, a fundamental study only recently showed that the particle formation mechanism is different than previously hypothesized [9], which illustrates that expanding our basic knowledge will improve clinically-relevant formulations.

Encouragingly, a number of recent high-impact studies from established labs focus on the type of novelty that will allow the field to advance nanomedicine translation. While focusing on nano-bio interactions, Palomba et al. demonstrated that phagocytotic cells' recognition and uptake of nanoconstructs can be modulated by altering particle 'softness' in addition to previously reported parameters such as size, shape, and surface properties [10]. With phagocytes' importance in nanotherapy becoming increasingly clear, this insight may prove valuable in developing nanomedicine applications. Zhao and colleagues used a prodrug modification approach to optimize drug-carrier compatibility and improve nanotherapeutic efficacy. This is a departure from the conventional paradigm in which formulations are adapted to drugs. The study demonstrated the feasibility of exploiting a single platform - or a limited set of well-characterized nanoparticle platforms - to deliver a wide variety of drugs [11]. Complementing this approach, in vivo screening nanoparticle mini-libraries is a potent approach to improving nanotherapeutic function [12]. In an elegant example of a translational combination treatment strategy, Miller et al. demonstrated that priming the tumor microenvironment with radiation therapy and cyclophosphamide improves the tumor accumulation and therapeutic effects of established nanomedicines, mediated by tumor-associated macrophages [13].

The zebrafish has been proposed as a cost- and time-effective in vivo screening tool to assess nanoparticle pharmacokinetics early in the development cascade. This approach provides the opportunity to preselect promising lead formulations under complex physiological conditions and to investigate the molecular basis of nano-bio interactions $[14,15]$. New tools such as microfluidics and 3D bioprinting might offer additional ways to model in vivo situations better than standard in vitro experiments [16]. Finally, computational analysis of large datasets may facilitate the development of better models, for example to rationally design nanomedicines and/or accurately predict their 'in vivo behavior' $[17,18]$.

Do these highlighted studies and technological innovations imply that our field should no longer strive to develop novel materials for drug delivery? Obviously not, but novel materials should serve a well-defined purpose rather than themselves being the focus. Great examples of how material science has advanced clinically relevant nanomedicines include using polyethylene glycol to modify nanocarrier surfaces in order to increase circulation times or developing ionizable cationic lipids for nucleic acid therapeutics $[19,20]$. Nevertheless, in order to drive nanomedicines' clinical translation, we should adopt a more critical and realistic view of what constitutes a novel nanomaterial in a proof-of-principle study versus what constitutes an actual nanomedicine that has the potential to benefit patients. In addition, adequate patient stratification is required to improve the outcomes of clinical trials and ultimately increase nanomedicines' clinical success [21-23].

\section{How to implement improvements?}

Impact factors, number of citations, and h-factors: these measurements of success and prestige drive both early and established scientists to aim for top-tier journals and execute their studies according to the novelty and innovation requirements set by these journals' editors. In the field of nanomedicine, this dynamic has incentivised the strong focus on novel materials, rather than comprehensive studies of nanomedicines' real applicability. As illustrated by the studies noted above, several nanomedicine labs have recognized the need for in-depth studies and initiated research programs accordingly. We believe high-impact journals need to follow this trend, and their editors should be more accepting of studies in which the novelty is not primarily the material but rather the study's experimental design or its thorough investigation of nanoparticle in vivo behavior using state-of-the-art experimental methods. This shift in focus will be an important step toward improved understanding and clinical translation.

Standardizing nanomaterial characterization and reproducibility of experimental results are also issues in the field which need to be addressed [24-27]. The gradual movement toward full open access, preprint servers like bioRxiv (biorxiv.org), and ongoing technological innovations increasingly provide opportunities to exchange experimental results [28]. For example, several journals have introduced the option to publish data (e.g. detailed experimental settings for physicochemical nanoparticle characterization or outcomes of pharmacokinetic and biodistribution studies) as interactive notebook interfaces using Mathematica (wolfram.com/mathematica) or Jupyter (jupyter.org). This facilitates data visualization and allows for straightforward data interpretation and comparison, thereby improving reproducibility [29].

It is important to mention that in addition to scientists and publishers, policymakers and funding agencies can also contribute to improving nanomedicine research. For example, some of the field's grants may become more restrictive and dedicated to specific questions or challenges in existing (clinically approved) nanomedicine applications. Assessing individual scientists' grant applicants may be improved by considering the impact of "their entire body of work", not only the journal in which they are published [30]. This can easily be done using article metrics (e.g. citations, reads, downloads, social media mentions) analyzed by platforms like PlumX (plumanalytics.com) or Altmetric (altmetric.com). Additionally, implementing online interviews with an expert panel to select pre-proposals is one option to improve traditional grant assessments. By allowing applicants and reviewers to discuss the research proposal and its clinical relevance, such interviews would make the grant process more transparent, fair, and efficient.

Finally, a recent analysis showed that young scientists in biomedical research are more likely than more established researchers to be innovative and to adopt new approaches [31,32]. Hence, young researchers may significantly contribute to realizing the shift in our field we advocate. Funding agencies could include young investigators in review panels, which may facilitate faster implementation of new ideas and approaches. In line with this, as well as with the dwindling funding for successful young researches, the U.S. National Academies of Sciences, Engineering, and Medicine recently recommended significantly increasing the NIH budget for supporting early-career scientists in biomedical research [33].

\section{Outlook}

Over the last decades, many proof-of-principle studies on increasingly advanced nanoformulations have inspired young investigators like us to start research careers in nanomedicine. Although these studies have been important in establishing the field, to achieve significant clinical impact, we urgently need to improve our fundamental under- 
standing of nanomedicines' in vivo behavior. There are many exciting opportunities for drug delivery systems and nanomedicines, such as (multimodal) combination treatments, immunotherapy, and gene silencing, expression, or editing. As several leading research groups have already adapted their focus from formulation development to integrative approaches that improve our knowledge of nanomedicines and potentiate their effects, we believe our field has a bright future ahead. As young investigators, we should strive to burst the 'The Novelty Bubble' in order to ensure that nanomedicines truly impact patients rather than just generating more publications.

\section{Acknowledgements}

The authors thank Prof. T. Lammers and Prof. W.J.M. Mulder for critically reading the manuscript. DW is supported by an Early Postdoc.Mobility Fellowship from the Swiss National Science Foundation (SNF grant No. 174975). SH is supported by funding from the Research Council of Norway (RCN, \#230788/F20). RvdM is supported by a Veni Fellowship (\#14385) from The Netherlands Organization for Scientific Research (NWO).

\section{References}

[1] J.C. Leroux, The novelty bubble, J. Control. Release 278 (2018) 140-141.

[2] M. Bjornmalm, K.J. Thurecht, M. Michael, A.M. Scott, F. Caruso, Bridging bio-nano science and cancer nanomedicine, ACS Nano 11 (2017) 9594-9613.

[3] T. Lammers, F. Kiessling, M. Ashford, W. Hennink, D. Crommelin, G. Storm, Cancer nanomedicine: Is targeting our target?, Nat. Rev. Mater. 1 (2016), 16069.

[4] L.D. Mayer, T.O. Harasym, P.G. Tardi, N.L. Harasym, C.R. Shew, S.A. Johnstone, E.C. Ramsay, M.B. Bally, A.S. Janoff, Ratiometric dosing of anticancer drug combinations: Controlling drug ratios after systemic administration regulates therapeutic activity in tumor-bearing mice, Mol. Cancer Ther. (5) (2006) 1854-1863.

[5] R. van der Meel, L.J. Vehmeijer, R.J. Kok, G. Storm, E.V. van Gaal, Ligand-targeted particulate nanomedicines undergoing clinical evaluation: Current status, Adv. Drug Deliv. Rev. 65 (2013) 1284-1298.

[6] A. Wicki, D. Witzigmann, V. Balasubramanian, J. Huwyler, Nanomedicine in cancer therapy: Challenges, opportunities, and clinical applications, J. Control. Release 200 (2015) 138-157.

[7] K. Raemdonck, S.C. De Smedt, Lessons in simplicity that should shape the future of drug delivery, Nat. Biotechnol. 33 (2015) 1026-1027.

[8] D. Adams, A. Gonzalez-Duarte, W.D. O'Riordan, C.C. Yang, M. Ueda, A.V. Kristen, I. Tournev, H.H. Schmidt, T. Coelho, J.L. Berk, K.P. Lin, G. Vita, S. Attarian, V. Plante-Bordeneuve, M.M. Mezei, J.M. Campistol, J. Buades, T.H. Brannagan, B.J. Kim 3rd, J. Oh, Y. Parman, Y. Sekijima, P.N. Hawkins, S.D. Solomon, M. Polydefkis, P.J. Dyck, P.J. Gandhi, S. Goyal, J. Chen, A.L. Strahs, S.V. Nochur, M.T. Sweetser, P.P. Garg, A.K. Vaishnaw, J.A. Gollob, O.B. Suhr, Patisiran, an RNAi therapeutic, for hereditary transthyretin amyloidosis, N. Engl. J. Med. 379 (2018) $11-21$.

[9] J.A. Kulkarni, M.M. Darjuan, J.E. Mercer, S. Chen, R. van der Meel, J.L. Thewalt, Y.Y.C. Tam, P.R. Cullis, On the formation and morphology of lipid nanoparticles containing ionizable cationic lipids and siRNA, ACS Nano 12 (2018) 4787-4795.

[10] R. Palomba, A.L. Palange, I.F. Rizzuti, M. Ferreira, A. Cervadoro, M.G. Barbato, C. Canale, P. Decuzzi, Modulating phagocytic cell sequestration by tailoring nanoconstruct softness, ACS Nano 12 (2018) 1433-1444.

[11] Y. Zhao, F. Fay, S. Hak, J. Manuel Perez-Aguilar, B.L. Sanchez-Gaytan, B. Goode, R. Duivenvoorden, C. de Lange Davies, A. Bjorkoy, H. Weinstein, Z.A. Fayad, C. Perez-Medina, W.J. Mulder, Augmenting drug-carrier compatibility improves tumour nanotherapy efficacy, Nat. Commun. 7 (2016), 11221.

[12] J. Tang, S. Baxter, A. Menon, A. Alaarg, B.L. Sanchez-Gaytan, F. Fay, Y. Zhao, M. Ouimet, M.S. Braza, V.A. Longo, D. Abdel-Atti, R. Duivenvoorden, C. Calcagno, G. Storm, S. Tsimikas, K.J. Moore, F.K. Swirski, M. Nahrendorf, E.A. Fisher, C. Perez-Medina, Z.A. Fayad, T. Reiner, W.J. Mulder, Immune cell screening of a nanoparticle library improves atherosclerosis therapy, Proc. Natl. Acad. Sci. U. S. A. 113 (2016) E6731-E6740.
[13] M.A. Miller, R. Chandra, M.F. Cuccarese, C. Pfirschke, C. Engblom, S. Stapleton, U. Adhikary, R.H. Kohler, J.F. Mohan, M.J. Pittet, R. Weissleder, Radiation therapy primes tumors for nanotherapeutic delivery via macrophage-mediated vascular bursts, Sci. Transl. Med. 9 (2017).

[14] S. Sieber, P. Grossen, P. Detampel, S. Siegfried, D. Witzigmann, J. Huwyler, Zebrafish as an early stage screening tool to study the systemic circulation of nanoparticulate drug delivery systems in vivo, J. Control. Release 264 (2017) 180-191.

[15] F. Campbell, F.L. Bos, S. Sieber, G. Arias-Alpizar, B.E. Koch, J. Huwyler, A. Kros, J. Bussmann, Directing nanoparticle biodistribution through evasion and exploitation of stab2-dependent nanoparticle uptake, ACS Nano 12 (2018) 2138-2150.

[16] Y.S. Zhang, A. Khademhosseini, Seeking the right context for evaluating nanomedicine: From tissue models in petri dishes to microfluidic organs-on-a-chip, Nanomedicine (London) 10 (2015) 685-688.

[17] A. Cern, D. Marcus, A. Tropsha, Y. Barenholz, A. Goldblum, New drug candidates for liposomal delivery identified by computer modeling of liposomes' remote loading and leakage, J. Control. Release 252 (2017) 18-27.

[18] P. Hassanzadeh, F. Atyabi, R. Dinarvand, Ignoring the modeling approaches: Towards the shadowy paths in nanomedicine, J. Control. Release 280 (2018) 58-75.

[19] S.C. Semple, A. Akinc, J. Chen, A.P. Sandhu, B.L. Mui, C.K. Cho, D.W. Sah, D. Stebbing, E.J. Crosley, E. Yaworski, I.M. Hafez, J.R. Dorkin, J. Qin, K. Lam, K.G. Rajeev, K.F. Wong, L.B. Jeffs, L. Nechev, M.L. Eisenhardt, M. Jayaraman, M. Kazem, M.A. Maier, M. Srinivasulu, M.J. Weinstein, Q. Chen, R. Alvarez, S.A. Barros, S. De, S.K. Klimuk, T. Borland, V. Kosovrasti, W.L. Cantley, Y.K. Tam, M. Manoharan, M.A. Ciufolini, M.A. Tracy, A. de Fougerolles, I. MacLachlan, P.R. Cullis, T.D. Madden, M.J. Hope, Rational design of cationic lipids for siRNA delivery, Nat. Biotechnol. 28 (2010) 172-176.

[20] T.M. Allen, C. Hansen, F. Martin, C. Redemann, A. Yau-Young, Liposomes containing synthetic lipid derivatives of poly(ethylene glycol) show prolonged circulation half-lives in vivo, Biochim. Biophys. Acta 1066 (1991) 29-36.

[21] M.A. Miller, S. Arlauckas, R. Weissleder, Prediction of anti-cancer nanotherapy efficacy by imaging, Nano 1 (2017) 296-312.

[22] H. Lee, A.F. Shields, B.A. Siegel, K.D. Miller, I. Krop, C.X. Ma, P.M. Lorusso, P.N. Munster, K. Campbell, D.F. Gaddy, S.C. Leonard, E. Geretti, S.J. Blocker, D.B. Kirpotin, V. Moyo, T.J. Wickham, B.S. Hendriks, (64)Cu-MM-302 positron emission tomography quantifies variability of enhanced permeability and retention of nanoparticles in relation to treatment response in patients with metastatic breast cancer, Clin. Cancer Res. 23 (2017) 4190-4202.

[23] R.K. Ramanathan, R.L. Korn, N. Raghunand, J.C. Sachdev, R.G. Newbold, G. Jameson, G.J. Fetterly, J. Prey, S.G. Klinz, J. Kim, J. Cain, B.S. Hendriks, D.C. Drummond, E. Bayever, J.B. Fitzgerald, Correlation between ferumoxytol uptake in tumor lesions by MRI and response to nanoliposomal irinotecan in patients with advanced solid tumors: A pilot study, Clin. Cancer Res. 23 (2017) 3638-3648.

[24] A. Tropsha, K.C. Mills, A.J. Hickey, Reproducibility, sharing and progress in nanomaterial databases, Nat. Nanotechnol. 12 (2017) 1111-1114.

[25] J.B. Coty, C. Vauthier, Characterization of nanomedicines: A reflection on a field under construction needed for clinical translation success, J. Control. Release 275 (2018) 254-268.

[26] K.A. Howard, D. Peer, Providing the full picture: A mandate for standardizing nanoparticle-based drug delivery, Nanomedicine (London) 8 (2013) 1031-1033.

[27] M. Faria, M. Bjornmalm, K.J. Thurecht, S.J. Kent, R.G. Parton, M. Kavallaris, A.P.R. Johnston, J.J. Gooding, S.R. Corrie, B.J. Boyd, P. Thordarson, A.K. Whittaker, M.M. Stevens, C.A. Prestidge, C.J.H. Porter, W.J. Parak, T.P. Davis, E.J. Crampin, F. Caruso, Minimum information reporting in bio-nano experimental literature, Nat. Nanotechnol. 13 (2018) 777-785.

[28] S. Kunjachan, S. Kotb, R. Kumar, R. Pola, M. Pechar, F. Gremse, R. Taleeli, F. Trichard, V. Motto-Ros, L. Sancey, A. Detappe, A. Protti, I. Shanmugam, T. Ireland, T. Etrych, S. Sridhar, O. Tillement, G.M. Makrigiorgos, R. Berbeco, Targeted Drug Delivery by Radiation-Induced Tumor Vascular Modulation, bioRxiv, 268714 , 2018https://doi.org/10.1101/268714.

[29] J.M. Perkel, Data visualization tools drive interactivity and reproducibility in online publishing, Nature 554 (2018) 133-134.

[30] W. Chan, What is the value of publishing?, ACS Nano 12 (2018) 6345-6346.

[31] E. Callaway, Young scientists lead the way on fresh ideas, Nature 518 (2015) 283-284.

[32] M. Packalen, J. Bhattacharya, Age and the Trying Out of New Ideas, The National Bureau of Economic Research Working Paper Series, 2015, Working Paper No. 20920.

[33] E. National Academies of Sciences, Medicine, The Next Generation of Biomedical and Behavioral Sciences Researchers: Breaking Through, The National Academies Press, Washington, DC, 2018. 